\title{
DISCUSSION
}

\section{Discrete framework for limit equilibrium analysis of fibre-reinforced soil}

\author{
J. G. ZORNBERG (2002). Géotechnique 52, No. 8, 593-604
}

K. S. Heineck and N. C. Consoli, Federal University of Rio Grande do SuI, Brazil

The author has proposed an interesting and relevant methodology to analyse the limit equilibrium of fibrereinforced soil using a discrete approach conducted by independent characterisation of soil and fibre specimens. It is the range of applicability and accuracy of the author's proposed methodology in determining the critical normal stress, and shear strength parameters when failure is governed by fibre pullout or tensile breakage of the fibres, that are the main subjects of our discussion.

The discussers would like to argue on the basis of recent data from laboratory drained and undrained triaxial tests on fibre-reinforced/unreinforced non-plastic silty-sand carried out at Federal University of Rio Grande do SuI, Brazil (Reineck, 2002; Consoli et al., 2003). Specimens were statically compacted to optimum moisture content of $16 \cdot 2 \%$ and maximum dry unit weight of $17.4 \mathrm{kN} / \mathrm{m}^{3}$ from standard Proctor compaction tests. Triaxial tests were carried out with the samples fully saturated using effective confining pressures varying from 20 to $4500 \mathrm{kN} / \mathrm{m}^{2}$, covering all possible range of engineering applications. Saturation was monitored in each test, ensuring $B$ values of at least 0.97 for all specimens. The unreinforced tests yielded an effective shear strength envelope defined by a cohesion of $11.2 \mathrm{kPa}$ and a friction angle of $30.5^{\circ}$, as seen in Fig. 12 (in which $s^{\prime}=\left(\sigma_{1}^{\prime}+\sigma_{3}^{\prime}\right) / 2$ and $\left.t=\left(\sigma_{1}^{\prime}-\sigma_{3}^{\prime}\right) / 2\right)$ and Table 4 .

In the author's testing programme, only the accuracy of the shear strength parameters for the first part of the failure envelope was tested, when failure is governed by fibre pullout. The predicted shear strength parameters for the second part of the failure envelope were not validated by the author, once the critical normal stress was too high. The discussers' results can be used to check the accuracy of the entire proposed methodology. A bilinear effective shear strength fibre-reinforced soil envelope was obtained as seen in Fig. 12 for tests with chopped polypropylene fibre $(0.5 \%$ by weight) $24 \mathrm{~mm}$ long and with a linear density of 3 denier, yielding an aspect ratio of 1128 , a specific gravity of 0.91 , a tensile strength of $120 \mathrm{MPa}$ and an elastic modulus of $3 \mathrm{GPa}$. The critical normal stress, obtained experimentally, was approximately $110 \mathrm{kPa}$. Shear strength parameters for the first part of the failure envelope, when failure is governed by fibre pullout, are a cohesion of $6.5 \mathrm{kPa}$ and a friction angle of $61 \cdot 3^{\circ}$. For the second part of the failure envelope, governed by tensile breakage of the fibres, they are a cohesion of $142.6 \mathrm{kPa}$ and a friction angle of $30.8^{\circ}$

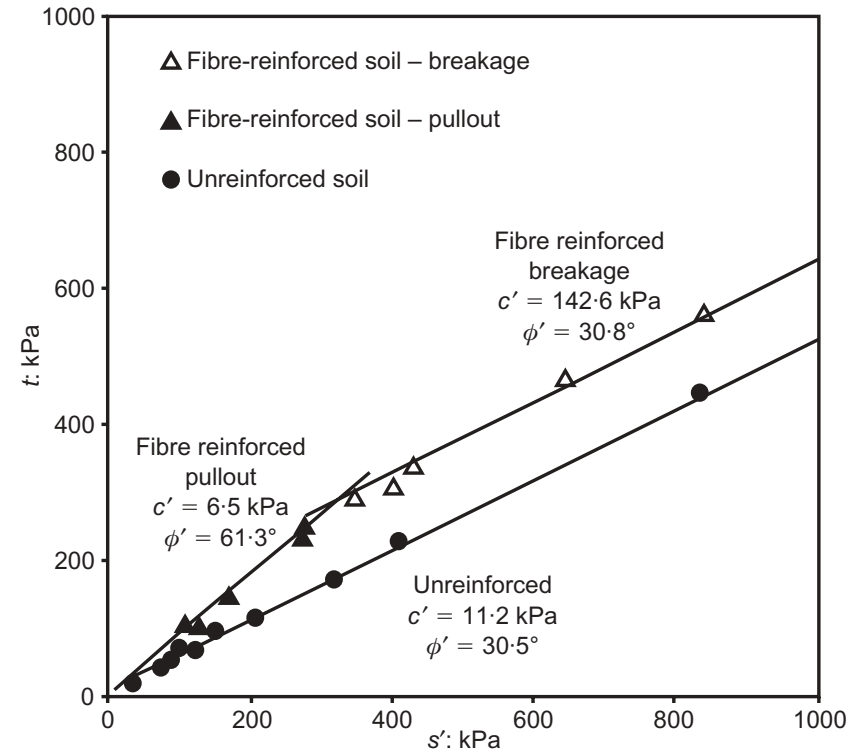

Fig. 12. Unreinforced soil and fibre-reinforced soil shear strength envelopes

(see Table 4). Analytically, based on the methodology proposed by the author, from equation (25), a critical normal stress of approximately $123 \cdot 2 \mathrm{kPa}$ was calculated, considering soil parameters of the unreinforced soil, as well as the fibre tensile strength and aspect ratio given above, and assuming $c_{\mathrm{i}, \mathrm{c}}=c_{\mathrm{i}, \phi}=0 \cdot 8$. The results are practically coincident, showing the accuracy of the author's proposed methodology in determining the critical normal stress. The equivalent shear strength parameters when failure is governed by fibre pullout, given by equations (32) and (33), yield $c_{\mathrm{eq}, \mathrm{p}}^{\prime}=109 \cdot 2 \mathrm{kPa}$ and $\phi_{\mathrm{eq}, \mathrm{p}}^{\prime}=80 \cdot 1^{\circ}$. This clarifies the inaccuracy in determining both the equivalent cohesion and the friction angle. For the failure envelope governed by tensile breakage of the fibres, given by equations (37) and (38), analytical results yield $c_{\text {eq, }}^{\prime}=1175.2 \mathrm{kPa}$ and $\phi_{\text {eq, }}^{\prime}=30 \cdot 5^{\circ}$. In this case, the cohesion intercept was overestimated, whereas the friction angle was almost exact. The discussers suppose that the difference between the experimental and analytical shear strength parameters is possibly caused by the value of the fibre linear density and aspect ratio, which are distinct from the range used by the author's

Table 4. Comparison between experimental and predicted fibre-reinforced soil parameters

\begin{tabular}{l|c|c|c|c|c}
\hline $\begin{array}{l}\text { Soil } \\
\text { parameters }\end{array}$ & $\begin{array}{c}\text { Unreinforced } \\
\text { soil }\end{array}$ & \multicolumn{2}{|c|}{$\begin{array}{c}\text { Fibre-reinforced soil } \\
\text { pullout }\end{array}$} & \multicolumn{2}{c}{$\begin{array}{c}\text { Fibre-reinforced soil } \\
\text { breakage }\end{array}$} \\
\cline { 3 - 6 } & & Experimental & Predicted & Experimental & Predicted \\
\hline$c^{\prime}: \mathrm{kPa}$ & $11 \cdot 2$ & $6 \cdot 5$ & $109 \cdot 2$ & $142 \cdot 6$ & $1175 \cdot 2$ \\
$\phi^{\prime}:$ degrees & $30 \cdot 5$ & $61 \cdot 3$ & $80 \cdot 1$ & $30 \cdot 8$ & $30 \cdot 5$ \\
\hline
\end{tabular}


testing programme. Therefore the interval of applicability of the author's proposed methodology should be validated by further experimental evidence.

\section{Author's reply}

The writer thanks the discussers for their interest in the discrete framework, and for their valuable input. The discussers conducted a series of triaxial tests on unreinforced and fibre-reinforced specimens. The reinforced specimens used very thin ( 3 denier or $0.023 \mathrm{~mm}$ diameter), $24 \mathrm{~mm}$ long fibres placed at a gravimetric fibre content of $0.5 \%$. The discussers found that the discrete framework predicts accurately both the critical normal stress, $\sigma_{\text {n,crit }}$ (that is, the normal stress below which fibres fail by pullout and above which fibres fail by breakage) and the friction angle of fibrereinforced specimens tested above $\sigma_{\mathrm{n}, \text { crit }}$ (that is, $\phi_{\text {eq, }}$ ). On the other hand, the discussers found that the discrete framework overpredicts the cohesion and friction angle of fibrereinforced specimens tested below $\sigma_{\mathrm{n}, \text { crit }}$ (that is, $\mathrm{c}_{\text {eq,p }}$ and $\left.\phi_{\text {eq,p }}\right)$ as well as the cohesion of fibre-reinforced specimens tested above $\sigma_{\mathrm{n}, \text { crit }}$ (that is $\mathrm{c}_{\mathrm{eq}, \mathrm{t}}$ ).

The discrete framework discussed in the paper assumes that the mixture is homogeneous and that the fibres are randomly distributed (at least for the cases in which the empirical coefficient $\alpha$ is assumed to equal 1.0). As mentioned by the author in the paper, it is anticipated that difficulty in achieving good fibre mixing may compromise the validity of the discrete framework for comparatively high fibre aspect ratios and for comparatively high fibre contents. The fibre aspect ratio and fibre content at which the validity of these relationships is compromised was not evaluated in the original study. This explanation agrees with the discussers' suggestion that the large aspect ratio of the fibres used in their study probably causes the discrepancy between experimental and predicted results. As discussed below, this author believes that not all fibres intercepted by the shear plane will be 'active' if very thin fibres (that is, fibres with very high aspect ratio) are used to reinforce a soil mass.

The linear densities of fibres available in the US market range from 360 to 3620 denier, which correspond to equivalent diameters ranging from 0.23 to $0.75 \mathrm{~mm}$. On the other hand, the linear density of the fibres used by the discussers equals 3 denier, which corresponds to an equivalent diameter of $0.023 \mathrm{~mm}$ and may be smaller than the soil particles of the reinforced mass. Quantifying the number of fibres in a triaxial specimen (e.g. $147 \mathrm{~mm}$ diameter with a length-todiameter ratio of 2 ) provides an additional perspective on the significance of the selected fibre linear density. Whereas a triaxial specimen reinforced with 3620 denier, $24 \mathrm{~mm}$ long fibres placed at $0.5 \%$ fibre content contains approximately 5000 fibres, a triaxial specimen reinforced with 3 denier, $24 \mathrm{~mm}$ long fibres placed at $0.5 \%$ fibre content would contain over 6000000 fibres. The author believes that such a large number of fibres per unit volume will lead to:

(a) non-uniformly mixed specimens

(b) differences between the actual fibre area in contact with soil and the theoretical area defined using the equivalent diameter

(c) fibres that remain undulated and entangled after placement because of their small transversal rigidity.

The last observation may be particularly significant, as the only fibres expected to develop tensile forces are the 'straight' ones intercepted by the failure plane, whereas the 'undulated' fibres are not expected to work until significant displacements have taken place.

In spite of the above discussion, the author believes that the discrete framework is also useful to predict the response of very thin fibres such as those used by the discussers. However, a coefficient $\alpha$ less than 1 would need to be adopted in this case to quantify the percentage of 'active' fibres. Interestingly, the two parameters that the discussers found to be well predicted by the discrete framework $\left(\sigma_{\mathrm{n}, \mathrm{crit}}\right.$ and $\left.\phi_{\text {eq, }}\right)$ are independent of the coefficient $\alpha$, whereas the parameters that the discussers found to be overpredicted by the discrete framework $\left(\mathrm{c}_{\mathrm{eq}, \mathrm{p}}, \phi_{\text {eq,p }}\right.$ and $\left.\phi_{\text {eq, }}\right)$ are affected by the coefficient $\alpha$ (the discussers used $\alpha=1.0$ in their predictions). The author found that a value of $\alpha$ of approximately $0 \cdot 12$ leads to parameters defining a bilinear envelope that is in good agreement with the experimental data.

Two of the parameters in the discrete framework developed by the author may need additional experimental calibration for certain fibre types. One of them is the equivalent diameter $d_{\mathrm{f}}$, which may not be accurately defined by equations (9) and (10) in the paper, particularly for fibres that do not have a circular cross-section. The other parameter is $\alpha$, which may be less than 1.0 for cases such as the one illustrated by the discussers. It is relevant for design purposes to note that, while this calibration requires additional experimental testing, the calibrated values are expected to be fibre type-specific. That is, the parameter value backcalculated from a shear strength envelope is expected to be useful for predicting shear strength envelopes of specimens prepared using the same fibre type but different soils and, to some extent, different fibre lengths.

\section{REFERENCES}

Consoli, N. C., Casagrande, M. D. T. Prietto, P. D. M. and Thomé, A. (2003). Plate Load Test on Fiber-Reinforced Soil, Journal of Geotechnical and Geoenvironmental Engineering, 129, No. 10, pp. 951-955.

Heineck, K. S. (2002). Mechanical and hydraulic behaviour of new geotechnical materials. $\mathrm{PhD}$ thesis, Federal University of Rio Grande do Sul, Porto Alegre, Brazil (in Portuguese). 